\title{
Use of the Pacifiers in Children with Disabilities
}

\author{
Sun Joung Leigh An* \\ Department of Occupational therapy, Inje University, Republic of Korea
}

*Corresponding author: Sun Joung Leigh An, Department of Occupational therapy,

Inje University, Republic of Korea.

Received Date: September 20, 2020

Published Date: October 05, 2020

\section{Opinion}

Pacifiers are commonly used with babies all around the world. Pacifiers are used primarily to stimulate sucking and to calm self. These pacifiers, "also known as soothers, dummies and artificial teats are as rooted in history as they are in controversy" [1]. Recommendations for and against its use are given to parents from various professionals including nurses, doctors, dentists and therapists grounded on the benefits or risks.

There are researches to show both potential benefits and risks for using pacifiers. Potential benefits of using pacifiers include self-comforting and calming [2], pain relief [3] and reduction in incidence of SIDS [4] and potential risks include fear of potential for malformation of teeth [5], negative impact on breastfeeding [6], cause otitis media [7] and negative impact on speech development [8]. However, "the body of research literature addressing the risks and benefits of pacifier usage is large and multidimensional and arrived at different conclusions, and made different, sometimes contradictory recommendations" [8] which have contributed to the already perplexing and controversial topic.

Due to decades of worldwide controversy, many parents continue to be in dilemma about whether to use or not use pacifiers with their infants and young children. Some parents even start following a recommendation from one professional and offer the pacifier to their infants then when they hear a different recommendation stop then go back and forth, reporting feeling confused and guilty.

Most studies to date have focused on the use of pacifiers, however, the purpose of this paper is to bring attention for the need to do research on the relationship between not using the pacifier and oral motor problems, especially for children with disabilities. This author has worked with children with disabilities for the last 30 years and observed that children who have a strong suckling reflex cannot suck on a pacifier and parents reported suckling as infants not liking the pacifier and as refusal. Many of the children whose parents reported as infants refusing to use the pacifiers were demonstrating a seeking sensory stimulation in their mouths by constantly chewing whatever was available to them including food, clothing items and writing utensils such as pencils and pens. These children also continued to exhibit suckling reflex as children when they were eating and poor oral motor control.

Researches to date have looked at the use of pacifiers and the effect in infants and however this author would like to suggest that researches be done to look at the long term effects of the use or nonuse of the pacifiers in relationship to oral motor control including feeding solids and speech in children with and without disabilities.

\section{Acknowledgement}

None.

\section{Conflict of Interest}

No conflict of interest.

\section{References}

1. Jenik AG, Vain N (2009) The pacifier debate. Early Hum Dev 85(10 Suppl): S89-S91.

2. Brazelton TB, Sparrow JD (2006) Touchpoints: The essential reference: Your child's emotional and behavioral development ( $2^{\text {nd }}$ Edn). MA: Perseus Publishing, Cambridge. 
3. Phillips RM, Chantry CJ, Gallagher MP (2005) Analgesic effects of breastfeeding or pacifier use with maternal holding in term infants. Ambul Pediatr 5(6): 359-364.

4. Hauck FR, Omojokun 00, Siadaty MS (2005) Do pacifiers reduce the risk of sudden infant death syndrome? A meta-analysis. Pediatrics 116(5): e716-e723.

5. Pansy J, Zotter H, Sauseng W, Schneuber S, Lang U, et al. (2008) Pacifier use: What makes mothers change their mind? Acta Paediatr 97(7): 968971.
6. Vogel AM, Hutchison BL, Mitchell EA (2001) The impact of pacifier use on breastfeeding: a prospective cohort study. J Paediatr Child Health 37(1): 58-63.

7. Hanafin S, Griffiths P (2002) Evidence based practice: Pacifier use and ear infections. Community Practitioner 75: 50-53.

8. Nelson AM (2012) A comprehensive review of evidence and current recommendations related to pacifier usage. J Pediatr Nurs 27(6): 690699. 